\title{
Article
}

\section{Design of an On-Chip Plasmonic Modulator Based on Hybrid Orthogonal Junctions Using Vanadium Dioxide}

\author{
Gregory Beti Tanyi *(1), Miao Sun, Christina Lim and Ranjith Rajasekharan Unnithan * \\ Department of Electrical and Electronic Engineering, Faculty of Engineering and Information Technology, \\ The University of Melbourne, Melbourne, VIC 3010, Australia; aussunnysun@gmail.com (M.S.); \\ chrislim@unimelb.edu.au (C.L.) \\ * Correspondence: gtanyi@student.unimelb.edu.au (G.B.T.); r.ranjith@unimelb.edu.au (R.R.U.); \\ Tel.: +61-3-8344-4733 (R.R.U.)
}

Citation: Tanyi, G.B.; Sun, M.; Lim,

C.; Unnithan, R.R. Design of an

On-Chip Plasmonic Modulator Based on Hybrid Orthogonal Junctions

Using Vanadium Dioxide.

Nanomaterials 2021, 11, 2507. https://

doi.org/10.3390/nano11102507

Academic Editor: Andrey

B. Evlyukhin

Received: 6 September 2021

Accepted: 22 September 2021

Published: 26 September 2021

Publisher's Note: MDPI stays neutral with regard to jurisdictional claims in published maps and institutional affiliations.

\begin{abstract}
We present the design of a plasmonic modulator based on hybrid orthogonal silver junctions using vanadium dioxide as the modulating material on a silicon-on-insulator. The modulator has an ultra-compact footprint of $1.8 \mu \mathrm{m} \times 1 \mu \mathrm{m}$ with a $100 \mathrm{~nm} \times 100 \mathrm{~nm}$ modulating section based on the hybrid orthogonal geometry. The modulator takes advantage of the large change in the refractive index of vanadium dioxide during its phase transition to achieve a high modulation depth of $46.89 \mathrm{~dB} / \mu \mathrm{m}$. The simulated device has potential applications in the development of next generation high frequency photonic modulators for optical communications which require nanometer scale footprints, large modulation depth and small insertion losses.
\end{abstract}

Keywords: electro-optics; modulators; nanophotonics; phase-changing materials; plasmonics

\section{Introduction}

Advances in nanofabrication in the past 30 years have led to the development of more compact and faster photonic and electro-optic devices [1-4]. Modulators are electrooptic devices that encode a high-speed electronic data stream to an optical carrier wave in photonic integrated circuits for optical communications. The size, power consumption and the frequency of operation are the key metrics used to evaluate performances of the modulators. Recently, there has been a surge in the development of novel modulators based on silicon photonics due to its compatibility with complementary metal-oxidesemiconductor (CMOS) technology [4]. This compatibility enables the integration of photonic circuits and electronic circuits in a single chip to increase the speed of operation and to reduce footprint [5].

However, reducing the footprint while keeping the speed of operation is still an ongoing challenge. This is because the footprints of conventional silicon photonics optical devices are limited by the diffraction limit. Also, silicon does not exhibit a linear electrooptic (EO) effect and thus silicon photonic modulators operate either on the dispersion effect or by integrating silicon with materials which exhibit an EO effect [5]. Silicon modulators based on the dispersion effect operate by varying the carrier concentration which in turn tunes the permittivity of silicon. This approach leads to limitations in the modulation depth, size and power requirements of the devices. The other approach which involves integrating silicon with EO materials requires a large interaction length (footprint) between the electrical signals and the optical signals.

To circumvent these constraints, plasmonic- based devices (surface plasmon polaritons (SPPs)) have been integrated in silicon photonics [6]. SPPs are electromagnetic surface waves at a dielectric-metal interface, coupled to the charge density oscillation in the metal surface $[5,6]$. SPPs offer the ability to focus light on nanoscales and are key elements in the development of subwavelength optical components with the added advantage of being 
compact and operating at much higher frequencies [1,6,7]. Recently, Graphene based plasmonic modulators have been used to achieve a modulation efficiency of $0.417 \mathrm{~dB} / \mu \mathrm{m}$ [8]. Also, plasmonic modulators based on the Pockels effect and operating at $40 \mathrm{GHz}$ have been developed using electro-optical polymers with a footprint of $29 \mu \mathrm{m}$ [9]. Designing plasmonic devices usually entails a trade-off between modulation depth, device size, loss and extinction ratio $[9,10]$. There is a demand for plasmonic modulators with small footprints, as well as low radiative and dissipative losses [5-7,9].

Vanadium dioxide $\left(\mathrm{VO}_{2}\right)$ is a canonical Mott material which exhibits a first order insulator to metal transition (IMT) which can be triggered by exciting the material thermally, electrically, or optically $[10,11]$. This phase transition is accompanied by a corresponding large change in the refractive index in the bulk material. It has been experimentally shown that an electric field strength of $6.5 \times 10^{7} \mathrm{~V} / \mathrm{m}$ would trigger the insulator to metal transition of $\mathrm{VO}_{2}[12,13]$. This phase transition occurs at the femto second scale $(26 \mathrm{fs})$ and as such, $\mathrm{VO}_{2}$ has been used as the modulating material in many high speed plasmonic devices. In [10], a thermally driven switch based on $\mathrm{VO}_{2}$ has been developed with an extinction ratio of $6.4 \mathrm{~dB} / \mu \mathrm{m}$ and a $5 \mu \mathrm{m}$ modulation section. However, thermally driven $\mathrm{VO}_{2}$ devices have a limited speed of operation. In [13-19], several $\mathrm{VO}_{2}$ based plasmonic modulators are explored. Some of these devices are limited by their footprint, while others require initial heating to trigger the transition due to the large size of the modulation section, and yet others have relatively low modulation depths.

In this paper, we report the simulation of a hybrid orthogonal plasmonic modulator with a $100 \mathrm{~nm} \times 100 \mathrm{~nm}$ modulation section within a compact device footprint of $1.8 \mu \mathrm{m} \times$ $1.0 \mu \mathrm{m}$. The electro-optic material of choice is vanadium dioxide due to the large change in the refractive index with the semiconductor phase having a refractive index of $3.24+0.30 \mathrm{i}$ and the metallic phase having a refractive index of $2.03+2.64 \mathrm{i}$ [12]. The optical modulation in this device is achieved by the large refractive index change of the nanoscale $\mathrm{VO}_{2}$ in the plasmonic slot under an external electric field. The orthogonal coupling geometry makes the device footprint small and provides a high modulation index of $46.89 \mathrm{~dB} / \mu \mathrm{m}$ at the telecommunication wavelength, $1550 \mathrm{~nm}$. Furthermore, the orthogonal geometry parameters are investigated and optimized with an in-depth simulation study, showing the device has a broad operating wavelength.

The rest of this paper is organized as follows: In Section 2, we present the general modulator design and its operation principle. In Section 3, we provide a discussion of the simulation methodology, perform an in-depth study on the performance of the device when tuning its geometry across a wide wavelength range and interpret the results obtained. Finally, a conclusion and brief discussion on areas of application of the device is given in Section 4.

\section{Materials and Methods}

The design of this modulator achieved with the following goals: maximizing the modulation depth and reducing the physical dimensions of the device, as well as minimizing the power consumption of the device while maintaining a broad wavelength of operation. The proposed modulator geometry is shown in Figure 1. The coupling scheme used is similar to the published work in [20] based on a metal-insulator-metal (MIM) plasmonic waveguide.

In this geometry, the light of wavelength $1550 \mathrm{~nm}$ travels in a silicon waveguide (width $430 \mathrm{~nm}$ and height $220 \mathrm{~nm}$ ) and is then coupled at the orthogonal silicon-air junction to a plasmonic slot waveguide (100 nm width and $1 \mu \mathrm{m}$ length). The plasmonic slot is made of $220 \mathrm{~nm}$ thick silver due to its relatively low plasmonic losses [21]. A $100 \mathrm{~nm}$ long section of $\mathrm{VO}_{2}$ is introduced at the center of the plasmonic slot as the modulating section. The silver electrodes can be extended via wire bonding and connected to an external voltage source to apply voltage across the slot to change the phase of $\mathrm{VO}_{2}$. At the second orthogonal junction, the plasmons are coupled back into photons and travel along the output silicon 
waveguide. A grating coupling scheme (not shown in the figure above) is used for coupling light in and out of the modulator.

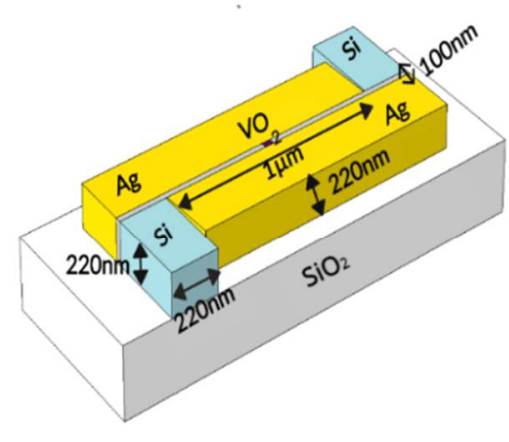

(a)

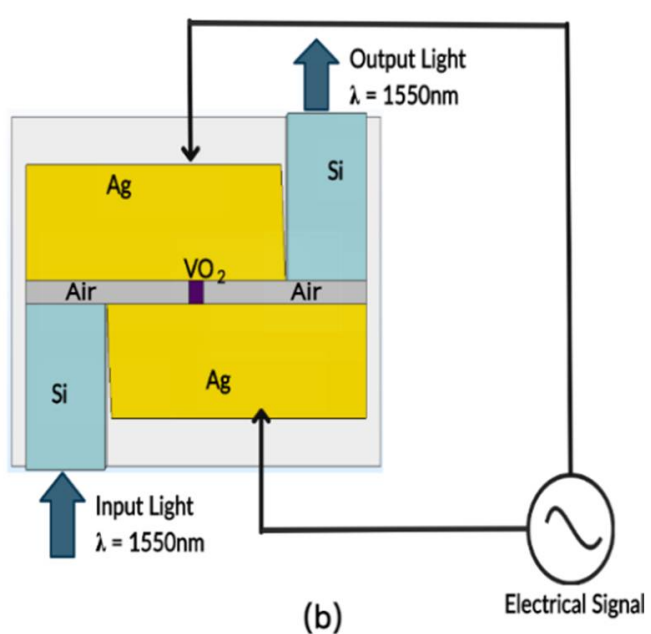

(b)

Figure 1. (a) Three-dimensional geometry of the proposed hybrid orthogonal plasmonic modulator. (b) Two-dimensional geometry of the proposed hybrid orthogonal plasmonic modulator showing light coupling directions. (Top layer of air not shown for visibility).

The device operates in 2 states depending on the application of an external electric field which drives the insulator to metal transition of the $\mathrm{VO}_{2}$ in the modulating section with. The refractive index of $\mathrm{VO}_{2}$ in both states is obtained from literature $[12,13]$. In the OFF state, there is no external electric field applied and hence $\mathrm{VO}_{2}$ in the modulating section is in the semiconductor phase with a refractive index of $(3.24+0.30 \mathrm{i})$. In this phase, surface plasmon polaritons travel across the modulating section and interact with $\mathrm{VO}_{2}$ in its semiconductor phase. In the ON state, there is an electric field strong enough to trigger the semiconductor to metal transition (IMT) of $\mathrm{VO}_{2}$. In the metallic phase, $\mathrm{VO}_{2}$ has a lower refractive index but higher extinction coefficient $(2.03+2.64 i)$ and which leads to the surface plasmon polaritons being attenuated by the $\mathrm{VO}_{2}$ section. The surface plasmon propagating in the slot through $\mathrm{VO}_{2}$ get modulated as it toggles between the $\mathrm{ON}$ and OFF states. The modulation depth is described as how much the modulation variable of a propagating carrier varies around its normal unmodulated level. Here, the modulation variable is the optical loss (attenuation). The optical loss is measured as the ratio of output power to the input power which are obtained by calculating the surface integral of the optical power at the silicon waveguides (input port and output ports) [22].

In the orthogonal modulator, the silicon waveguide has a width of $430 \mathrm{~nm}$ and a height of $220 \mathrm{~nm}$, the angular separation $(\theta)$ between the silicon waveguide and the silver electrode is $10^{\circ}$, the width of the plasmonic slot $(\mathrm{w})$ is $100 \mathrm{~nm}$ and the length of $\mathrm{VO}_{2}(\mathrm{~L})$ used is $100 \mathrm{~nm}$. Silver electrodes of height $220 \mathrm{~nm}$ are used as walls of the plasmonic slot, and the middle of the slot is filled with a $100 \mathrm{~nm}$ long section of $\mathrm{VO}_{2}$. The above parameters are optimized for operation in the C-band frequency range as shown in Figure $1 \mathrm{~b}$. The simulation details used to obtain the optimal parameters for the modulator along with the results are discussed in the following section.

\section{Simulation Results and Discussion}

We perform the modulator design, simulation and optimization using the finite element methods implemented in COMSOL Multiphysics commercial software (Version 5.2, COMSOL AB, Stockholm, Sweden). A minimum mesh element size of $6 \mathrm{~nm}$ is used in the plasmonic slot section which contains the smallest device features. Scattering boundary conditions (SBCs) are utilized to terminate the computational domain. The refractive indices of $\mathrm{VO}_{2}$ were obtained from literature as measured with the aid of variable angle 
spectroscopic ellipsometry as presented in $[12,13]$. Table 1 shows the material refractive index at the telecom wavelength $(1550 \mathrm{~nm})$.

Table 1. Material Refractive Index (1550 nm).

\begin{tabular}{cccc}
\hline $\mathbf{V O}_{2}$ (Semiconductor) & $\mathrm{VO}_{2}$ (Metallic) & $\mathrm{Si}$ & $\mathrm{SiO}_{2}$ \\
\hline $3.24+0.30 \mathrm{i}$ & $2.03+2.64 \mathrm{i}$ & 3.46 & 1.45 \\
\hline
\end{tabular}

Figure 2a shows a top view of the modulator in the OFF state. In this state, light in the silicon waveguide is coupled to the plasmonic slot and then propagates as SSPs through the slot interacting with $\mathrm{VO}_{2}$ in the semiconductor phase before being coupled back into light at the output waveguide. Figure $2 b$ shows the same top view of the device in the $\mathrm{ON}$ state. In the $\mathrm{ON}$ state, the metallic $\mathrm{VO}_{2}$ attenuates the travelling plasmons significantly, hence reducing the intensity of light coupled back at the output waveguide.

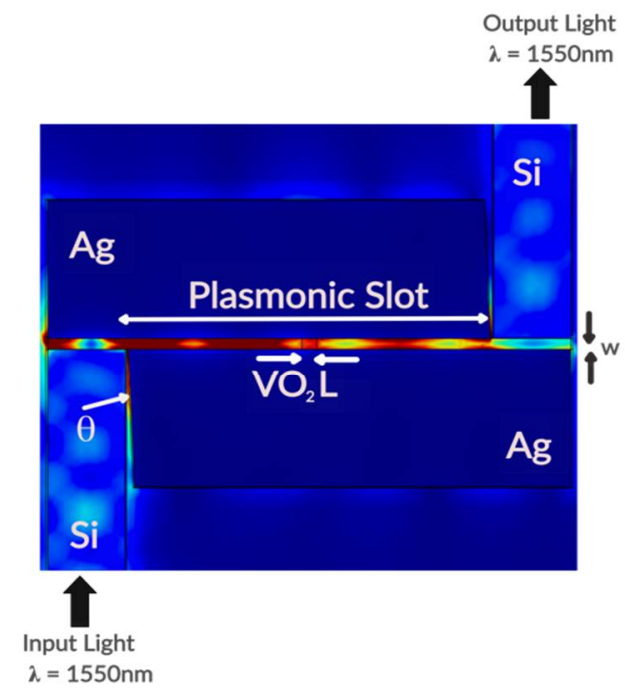

(a)

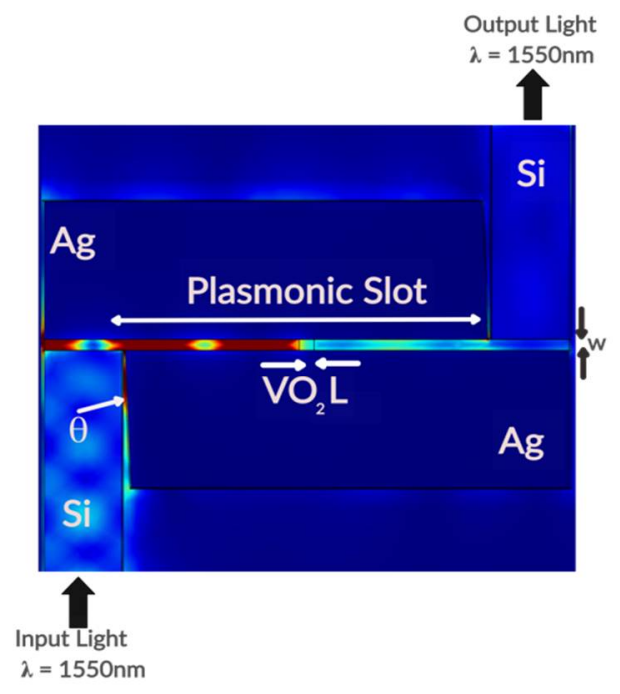

(b)

Figure 2. Planar cross-section view of device showing surface plot of electric field norm in (a) Left Semiconductor phase of $\mathrm{VO}_{2}$ (Device OFF) and (b) Right Metallic phase (Device ON) of $\mathrm{VO}_{2}$.

Figure $3 b, c$ show a cross section of the electric field across the $\mathrm{Ag}-\mathrm{VO}_{2}-\mathrm{Ag}$ plasmonic slot with a strong confinement of the electric field within the slot. It is observed that in the ON state of the device, the electric field intensity of plasmons is lower than in the OFF state because of the higher optical loss which accompanies the phase change of $\mathrm{VO}_{2}$ to the metallic phase. We further examine the electric field confinement in both states by examining the electric field intensity along a cutline in the modulating section of the plasmonic slot as shown in Figure 3a. To obtain the optical attenuation, we first calculate the ratio of the surface integral of the optical power Poynting vector (S) at both ends of the silicon waveguide which are the input and output ports [21,22]. The Poynting vector is obtained as

$$
\mathrm{S}\left[\mathrm{W} / \mathrm{m}^{2}\right]=\hat{\mathrm{n} I}
$$

The surface integral of the optical Poynting vector at the input and output ports give us the input power $\left(P_{\text {input }}\right)$ and output power $\left(P_{\text {output }}\right)$, respectively. The optical power $(P)$ and optical attenuation are given by the equations below:

$$
\begin{gathered}
\qquad \mathrm{P}=\iint \overrightarrow{\mathrm{S}} \cdot \hat{\mathrm{n}} \mathrm{da} \\
\text { Attenuation }(\mathrm{dB})=-10 \log \left(\frac{\mathrm{P}_{\text {output }}}{\mathrm{P}_{\text {input }}}\right)
\end{gathered}
$$


The modulation depth $(\mathrm{dB})$ is given by the difference in attenuation of the device in the OFF and ON states. It can be seen from Figure 3a that there is a significant drop in electric field intensity of the plasmons, which is consistent with Figure 2 and results from the interaction of the plasmons with $\mathrm{VO}_{2}$ in its metallic phase with a high extinction coefficient.

Figure $3 \mathrm{~d}$ shows the modulation depth of the device in both states along a range of wavelengths (1100-1800 nm) in the telecommunication. The device is optimized to have a minimal insertion loss around the $\mathrm{C}$ Band of the telecommunications window.

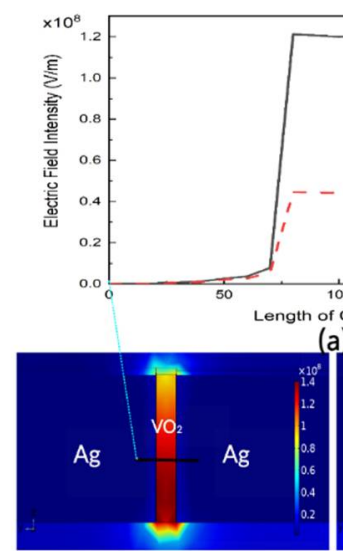

(b)

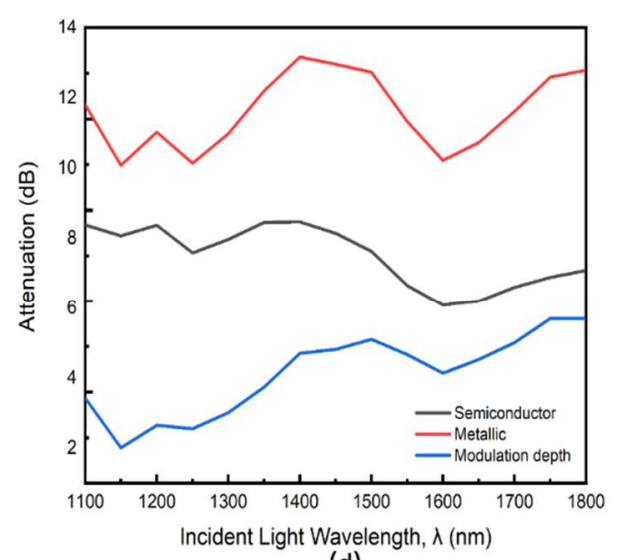

(d)

Figure 3. (a) Electric field Norm variation along cutline through plasmonic slot showing strong field confinement, Longitudinal cross section of the device in (b) OFF state $\left(\mathrm{VO}_{2}\right.$ in semiconductor phase) (c) ON state $\left(\mathrm{VO}_{2}\right.$ in metallic phase) (d) Insertion loss in both the metallic phase (ON phase) and the semiconductor phase (OFF phase) for incident light wavelength $(\lambda)$ swept from $1100 \mathrm{~nm}$ to $1800 \mathrm{~nm}$ from simulation study.

A key parameter that affects the level of modulation is the length $(\mathrm{L})$ of $\mathrm{VO}_{2}$ used in the device slot. In the simulations, the length (L) was varied from $50 \mathrm{~nm}$ to $170 \mathrm{~nm}$ at the $1550 \mathrm{~nm}$ wavelength while keeping the other parameters constant. These values were chosen because of the limitation of modern nanofabrication techniques and are well within the decay length of the plasmons. Figure 4a shows how the attenuation and modulation depth vary with the length of $\mathrm{VO}_{2}$ at $1550 \mathrm{~nm}$ wavelength. We observe a linear increase in attenuation as the length of $\mathrm{VO}_{2}$ in the slot is increased. This can be explained by the extinction coefficient of $\mathrm{VO}_{2}$ in both phases. Given $\mathrm{VO}_{2}$ is not a transparent material, the plasmons are attenuated when they interact with the modulating section and as such, increasing the length of $\mathrm{VO}_{2}$ means more interaction and hence loss in the plasmon energy. The higher loss in the metallic phase is because of a higher extinction coefficient in the metallic phase.

We also study the effect of varying the wavelength on the device performance. For this, we perform a wavelength sweep from $1100 \mathrm{~nm}$ to $1800 \mathrm{~nm}$ with the length (L) of $\mathrm{VO}_{2}$ varied from $50 \mathrm{~nm}$ to $170 \mathrm{~nm}$ and compare the attenuation in both the metallic and semiconductor phases. The results in Figure $4 \mathrm{~b}$ show that the device is robust enough to handle wavelength shifts due to transient temperature effects in high power laser systems. The trend of increased attenuation with an increase in length of $\mathrm{VO}_{2}$ is consistent in both Figure $4 a, b$. The slight dips at wavelengths $1150 \mathrm{~nm}$ and $1600 \mathrm{~nm}$ wavelengths are from the refractive index data used obtained from literature [12,13].

In the fabrication of the device, there is a need to understand the impact of the width of the plasmonic slot $(\mathrm{w})$ on the device performance, as well as the angle separating the electrodes from the waveguides $(\theta)$ given these constitute the critical dimensions of the device and are most susceptible to slight variations given the limitations of the current nanofabrication technology [23-30]. We thus study the impact of increasing the width of the plasmonic slot $(\mathrm{w})$ on the attenuation in both phases and the modulation depth. Figure $5 \mathrm{a}$ 
shows a decrease in modulation depth as the width is increased. This is because increasing the width of the plasmonic slot reduces the photon to plasmon coupling efficiency.

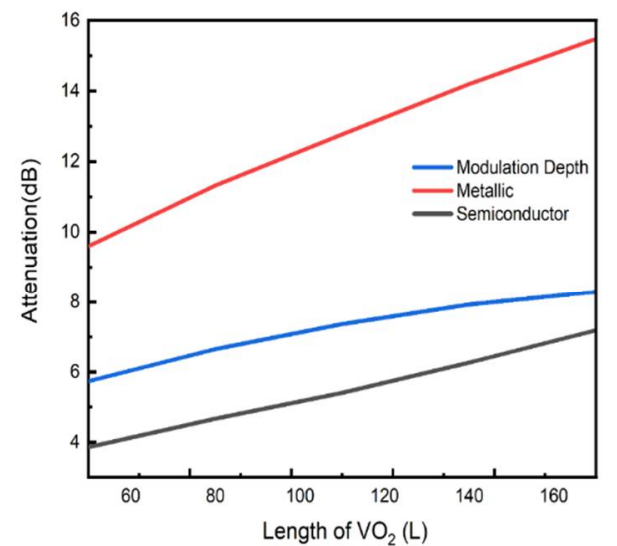

(a)

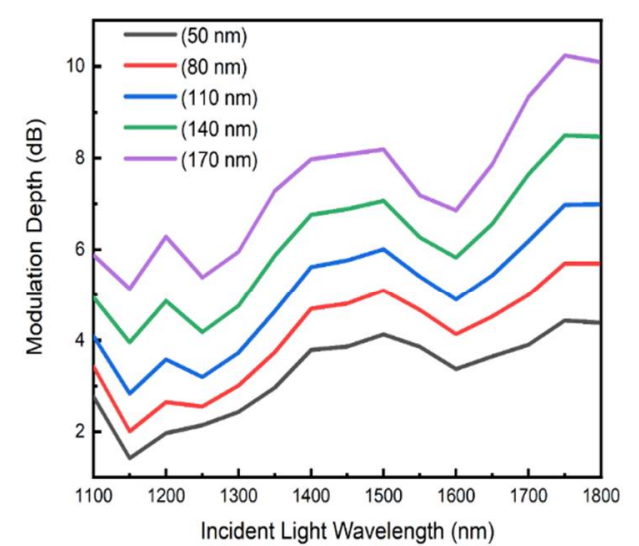

(b)

Figure 4. (a) Attenuation of light of wavelength $1550 \mathrm{~nm}$ for both the metallic and semiconductor phases of $\mathrm{VO}_{2}$ as well as the modulation depth for different lengths of the $\mathrm{VO}_{2}$ modulating section (L). (b) The variation of the modulation depth with different wavelengths of incident light $(\lambda)$ from $1100 \mathrm{~nm}$ to $1800 \mathrm{~nm}$, with the length of the $\mathrm{VO}_{2}$ modulating section (L) varied from $50 \mathrm{~nm}$ to $170 \mathrm{~nm}$.

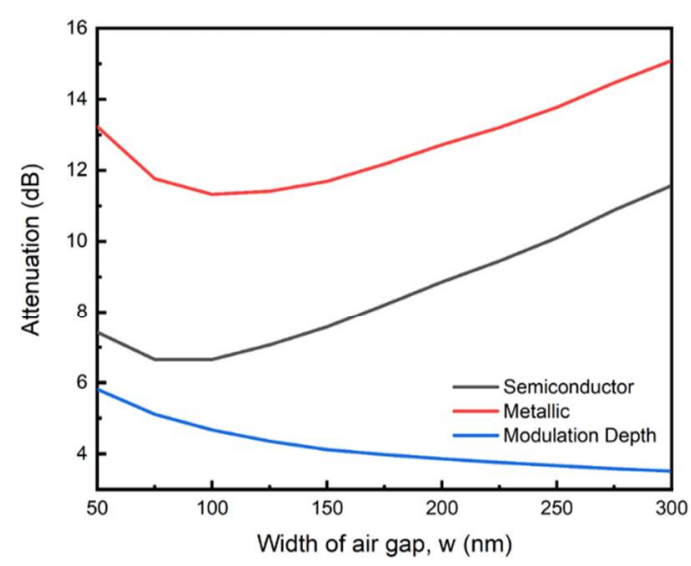

(a)

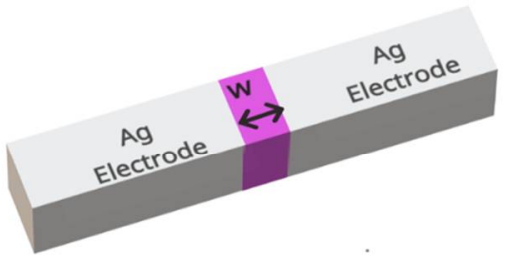

(b)

Figure 5. (a) Attenuation of light at $1550 \mathrm{~nm}$ for the metallic and semiconductor phases of $\mathrm{VO}_{2}$ with the modulation depth for different widths $w$ of the plasmonic slot. (b) Cross section of the plasmonic slot of width $(\mathrm{w})$ with violet colour representing $\mathrm{VO}_{2}$ and yellow colour representing Ag electrode.

The dependence of the modulation depth of the device on the angular separation is also studied by sweeping the angular separation $(\theta)$ from $0-80^{\circ}$. From the simulation results, we observe that the modulation depth reduces as the angular separation is increased. This is because a smaller angular separation accounts for a higher coupling efficiency.

Using only a $100 \mathrm{~nm}$ modulation section of $\mathrm{VO}_{2}$ and with the following optimal parameters $\left(\mathrm{w}=100 \mathrm{~nm}, \theta=8^{\circ}\right)$, we achieve a modulation depth of $4.69 \mathrm{~dB}(46.89 \mathrm{~dB} / \mu \mathrm{m})$. From Figures 2 and 3, a high extinction coefficient plays a key role in achieving such high modulation depth. We further investigate the effect of the phase change of $\mathrm{VO}_{2}$ on the coupling efficiency of this hybrid orthogonal geometry. In this hybrid-orthogonal geometry, the coupling efficiency is highly related to the momentum mismatch between the SPP mode and the waveguide $[9,23]$. Maximum coupling occurs when the orthogonal component of the momentum of the waveguide $\left(\mathrm{k}_{\mathrm{x}}\right)$ matches the fundamental mode of the plasmonic slot $\left(\mathrm{K}_{\mathrm{spp}}\right)$ and there is thus a minimal spatial mismatch. The schematics of this coupling scheme is illustrated in Figure 6b. In Figure 7, the longitudinal wave vector (and thus momentum) of the plasmonic slot with $\mathrm{VO}_{2}$ in both the metallic phase and semiconductor 
phase is compared to the orthogonal component of the waveguide's wave vector (and thus momentum). Figure 7 shows that at a wavelength of $1550 \mathrm{~nm}$, the plasmonic slot with $\mathrm{VO}_{2}$ in the semiconductor phase $\mathrm{K}_{\mathrm{spp}}$ equals $\mathrm{K}_{\mathrm{x}}$. Also, observing both curves shows the device has a higher coupling efficiency with $\mathrm{VO}_{2}$ in the semiconductor phase than the metallic phase, as the device was optimized for the semiconductor phase. This change in the coupling efficiency, as well as the high extinction ratio of $\mathrm{VO}_{2}$ lead to the high modulation depth as shown.

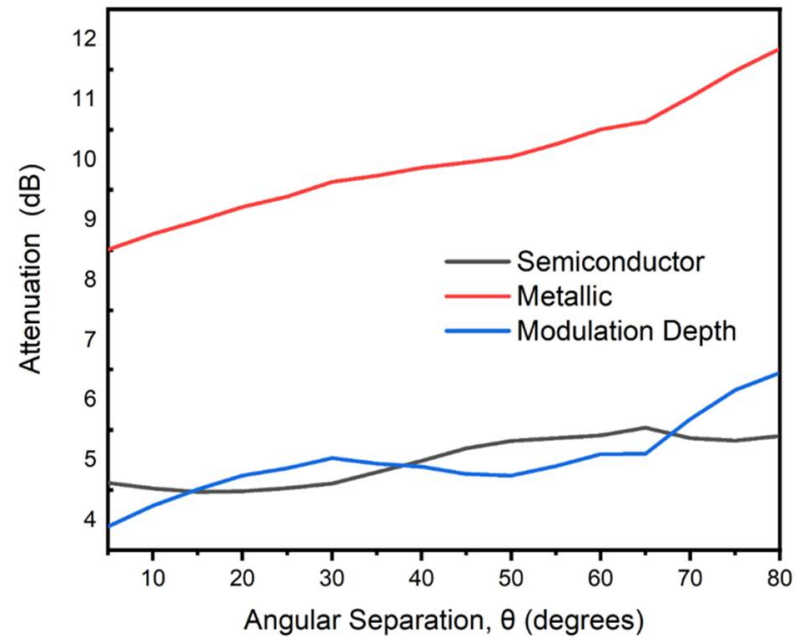

(a)

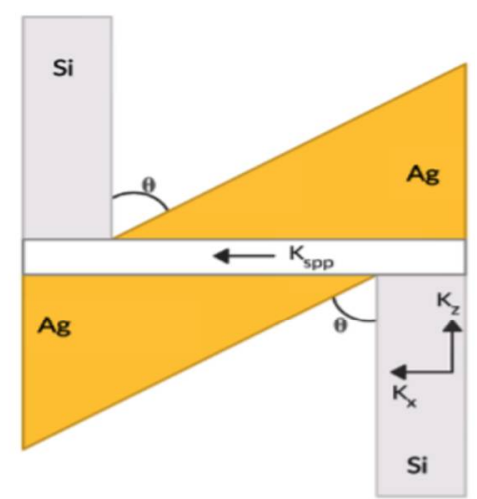

(b)

Figure 6. (a) Attenuation of Light at $1550 \mathrm{~nm}$ for the metallic and semiconductor phases of $\mathrm{VO}_{2}$ with the modulation depth for different angular separations $(\theta)$ between the Ag electrode and the silicon nanowire. (b) 2D-schematics of device with Silver highlighted in yellow and silicon highlighted in grey along with transverse component of silicon nanowires momentum $\left(\mathrm{k}_{\mathrm{x}}\right)$, orthogonal component of silicon waveguide momentum $\left(\mathrm{k}_{\mathrm{y}}\right)$ and surface plasmon polariton momentum annotated $\left(\mathrm{k}_{\mathrm{spp}}\right)$.

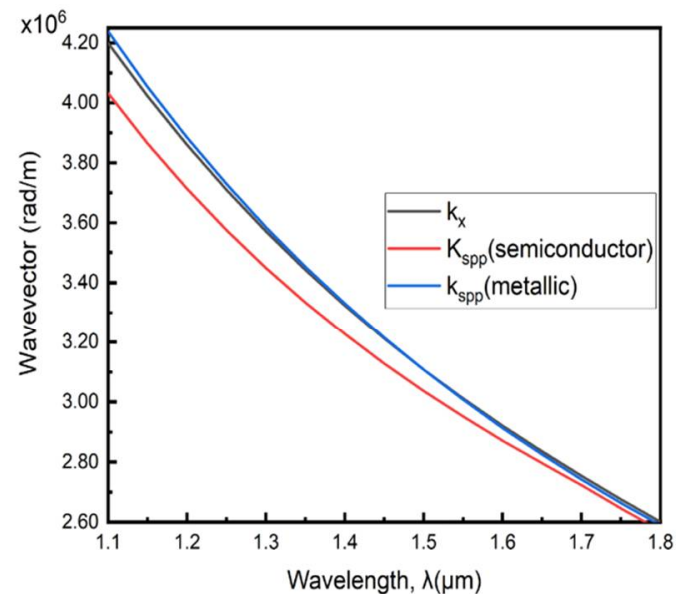

(a)

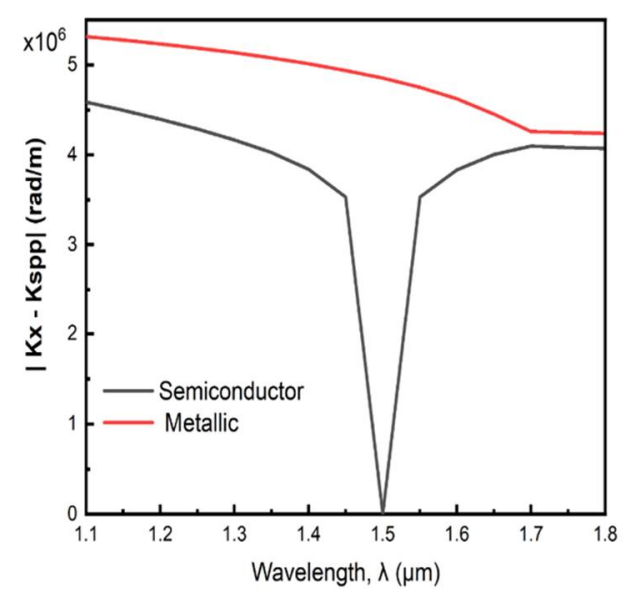

(b)

Figure 7. (a) Dispersion characteristics of the plasmonic slot and the silicon waveguide with $\mathrm{VO}_{2}$ in both the metallic and semiconductor phases. The slot width $(\mathrm{w})$ is $100 \mathrm{~nm}$, the silicon waveguide is $430 \mathrm{~nm}$ wide and $220 \mathrm{~nm}$ high (b) Absolute value of spatial mismatch in the metallic (ON) and metallic (OFF).

\section{Conclusions}

In this paper, we have demonstrated a hybrid orthogonal plasmonic modulator with a compact $100 \mathrm{~nm} \times 100 \mathrm{~nm}$ modulating section and a device footprint of $1.8 \mu \mathrm{m} \times 1 \mu \mathrm{m}$. The device uses Vanadium dioxide $\left(\mathrm{VO}_{2}\right)$ as the electrooptic material for intensity modulation 
and exploits the large change in the refractive index of $\mathrm{VO}_{2}$. The modulator is optimized for the $1550 \mathrm{~nm}$ telecommunications wavelength but can operate broadly in the O, E, S, C, $\mathrm{L}$ and $\mathrm{U}$ Bands (1260-1675 nm) and outperforms similar devices in literature to achieve a modulation depth of $46.89 \mathrm{~dB} / \mu \mathrm{m}$ at the $1550 \mathrm{~nm}$. The results will have applications in design of compact, cutting-edge high frequency modulators for high-speed optical communications.

Author Contributions: Conceptualization, G.B.T. and R.R.U.; methodology, G.B.T., R.R.U. and M.S.; Software, G.B.T.; validation, M.S. and R.R.U.; data curation, G.B.T. and M.S.; writing-original draft preparation, G.B.T.; writing-review and editing, M.S., R.R.U. and C.L.; visualization, G.B.T. project administration, R.R.U.; supervision, R.R.U. and C.L.; Funding Acquisition, R.R.U. and C.L. All authors have read and agreed to the published version of the manuscript.

Funding: This work was supported in part by the Australian Research Council No. DP170100363.

Conflicts of Interest: The authors declare no conflict of interest. The funders had no role in the design of the study; in the collection, analyses, or interpretation of data; in the writing of the manuscript, or in the decision to publish the results.

\section{References}

1. Rajasekharan, R.; Wilkinson, T.D.; Hands, P.J.W.; Dai, Q. Nanophotonic Three-Dimensional Microscope. Nano Lett. 2011, 11, 2770-2773. [CrossRef]

2. Yong, J.; Hassan, B.; Liang, Y.; Ganesan, K.; Rajasekharan, R.; Evans, R.; Egan, G.; Kavehei, O.; Li, J.; Chana, G.; et al. A Silk Fibroin Bio-Transient Solution Processable Memristor. Sci. Rep. 2017, 7, 14731. [CrossRef]

3. Rajasekharan, R.; Dai, Q.; Wilkinson, T.D. Electro-optic characteristics of a transparent nanophotonic device based on carbon nanotubes and liquid crystals. Appl. Opt. 2010, 49, 2099-2104. [CrossRef]

4. Chrostowski, L.; Hochberg, M. Silicon Photonics Design; Cambridge University Press: Cambridge, UK, 2016.

5. Jagadish, C.; Lourdudoss, S.; Bowers, J.E. Future Directions in Silicon Photonics, 1st ed.; Academic Press: Cambridge, MA, USA, 2019.

6. Gramotnev, D.K.; Bozhevolnyi, S. Plasmonics beyond the diffraction limit. Nat. Photon. 2010, 4, 83-91. [CrossRef]

7. Abate, Y.; Marvel, R.E.; Ziegler, J.I.; Gamage, S.; Javani, M.H.; Stockman, M.I.; Haglund, R.F. Control of plasmonic nanoantennas by reversible metal-insulator transition. Sci. Rep. 2015, 5, 13997. [CrossRef]

8. Zhou, F.; Liang, C. Highly tunable and broadband graphene ring modulator. J. Nanophotonics 2019, 13, 016008. [CrossRef]

9. Heni, W.; Haffner, C.; Elder, D.L.; Tillack, A.F.; Fedoryshyn, Y.; Cottier, R.; Salamin, Y.; Hoessbacher, C.; Koch, U.; Cheng, B.; et al. Nonlinearities of organic electro-optic materials in nanoscale slots and implications for the optimum modulator design. Opt. Express 2017, 25, 2627-2653. [CrossRef] [PubMed]

10. Olivares, I.; Sánchez, L.; Parra, J.; Larrea, R.; Griol, A.; Menghini, M.; Homm, P.; Jang, L.W.; van Bilzen, B.; Seo, J.W.; et al. Optical switching in hybrid $\mathrm{VO}_{2} / \mathrm{Si}$ waveguides thermally triggered by lateral microheaters. Opt. Express 2018, 26, 12387-12395. [CrossRef]

11. Jager, M.F.; Ott, C.; Kraus, P.M.; Kaplan, C.J.; Pouse, W.; Marvel, R.E.; Haglund, R.F.; Neumark, D.M.; Leone, S.R. Tracking the insulator-to-metal phase transition in $\mathrm{VO}_{2}$ with few-femtosecond extreme UV transient absorption spectroscopy. Proc. Natl. Acad. Sci. USA 2017, 36, 9558-9563. [CrossRef] [PubMed]

12. Verleur, H.; Barker, A.; Berglund, C. Optical Properties of $\mathrm{VO}_{2}$ between 0.25 and 5 eV. Phys. Rev. 1968, 172, 788-798. [CrossRef]

13. Earl, S.K.; James, T.D.; Davis, T.; McCallum, J.; Marvel, R.E.; Haglund, R.F.; Roberts, A. Tunable optical antennas enabled by the phase transition in vanadium dioxide. Opt. Express 2013, 21, 27503-27508. [CrossRef]

14. Sun, H.; Zhao, L.; Dai, J.; Liang, Y.; Guo, J.; Meng, H.; Liu, H.; Dai, Q.; Wei, Z. Broadband Filter and Adjustable Extinction Ratio Modulator Based on Metal-Graphene Hybrid Metamaterials. Nanomaterials 2020, 10, 1359. [CrossRef]

15. Markov, P.; Appavoo, K.; Haglund, R.F.; Weiss, S.M. Hybrid Si-VO $-\mathrm{Au}$ optical modulator based on near-field plasmonic coupling. Opt. Express 2015, 23, 6878-6887. [CrossRef] [PubMed]

16. Sun, M.; Shieh, W.; Unnithan, R.R. Design of Plasmonic Modulators with Vanadium Dioxide on Silicon-on-Insulator. IEEE Photonics J. 2017, 9, 4501010. [CrossRef]

17. Kim, Y.; Wu, P.C.; Sokhoyan, R.; Mauser, K.A.; Glaudell, R.; Shirmanesh, G.K.; Atwater, H.A. Phase Modulation with Electrically Tunable Vanadium Dioxide Phase-Change Metasurfaces. Nano Lett. 2019, 19, 3961-3968. [CrossRef] [PubMed]

18. Olyaee, M.; Tavakoli, M.B.; Mokhtari, A. Analyze and calculation of coupling coefficient based on evanescence field for plasmonic directional coupler structure. Opt. Quantum Electron. 2018, 50, 404. [CrossRef]

19. Markov, P.; Marvel, R.E.; Conley, H.J.; Miller, K.J.; Haglund, J.R.F.; Weiss, S.M. Optically Monitored Electrical Switching in VO 2 . ACS Photon. 2015, 2, 1175-1182. [CrossRef]

20. Lau, B.; Swillam, M.A.; Helmy, A.S. Hybrid orthogonal junctions: Wideband plasmonic slot-silicon waveguide couplers. Opt. Express 2010, 18, 27048-27059. [CrossRef] 
21. Zouhdi, S.; Sihvola, A. (Eds.) Metamaterials and Plasmonics: Fundamentals, Modelling, Applications; Springer: Dordrecht, The Netherlands, 2009.

22. Cheng, D. Field and Wave Electromagnetics; Pearson Education Limited: Harlow, UK, 2014.

23. Noghani, M.T.; Samiei, M.H.V. Propagation Characteristics of Multilayer Hybrid Insulator-Metal-Insulator and Metal-InsulatorMetal Plasmonic Waveguides. Adv. Electromagn. 2014, 2, 35-43. [CrossRef]

24. Kruger, B.A.; Joushaghani, A.; Poon, J.K.S. Design of electrically driven hybrid vanadium dioxide $\left(\mathrm{VO}_{2}\right)$ plasmonic switches. Opt. Express 2012, 20, 23598-23609. [CrossRef]

25. Rajasekharan, R.; Butt, H.; Dai, Q.; Wilkinson, T.D.; Amaratunga, G.A.J. Can Nanotubes Make a Lens Array? Adv. Mater. 2012, 24, OP170-OP173. [CrossRef] [PubMed]

26. Wu, B.; Zimmers, A.; Aubin, H.; Ghosh, R.; Liu, Y.; Lopez, R. Electric-field-driven phase transition in vanadium dioxide. Phys. Rev. B 2011, 84, 241410. [CrossRef]

27. Zhang, C.; Wang, D.; Huang, S.; Yang, J.; Liu, J.; Fang, J. Nonlinear Optical Response of Gold Nanobipyramids for a Doubly Q-Switched Ho-Doped Laser at a Wavelength of $2.1 \mu \mathrm{m}$. Nanomaterials 2021, 11, 535. [CrossRef] [PubMed]

28. Sopko, I.M.; Knyazev, G.A. Optical modulator based on acousto-plasmonic coupling. Phys. Wave Phenom. 2016, 24, 124-128. [CrossRef]

29. Salamin, Y.; Baeuerle, B.; Heni, W.; Abrecht, F.C.; Josten, A.; Fedoryshyn, Y.; Haffner, C.; Bonjour, R.; Watanabe, T.; Burla, M.; et al. Author Correction: Microwave plasmonic mixer in a transparent fibre-wireless link. Nat. Photon. 2018, 12, 790. [CrossRef]

30. Xu, X.; Chung, C.-J.; Pan, Z.; Yan, H.; Chen, R.T. Periodic waveguide structures for on-chip modulation and sensing. Jpn. J. Appl. Phys. 2018, 57, 08PA04. [CrossRef] 